\title{
Characters of Innovation Management in the Primary Health Care Centers
}

\author{
Alireza Aslani, Marja Naaranoja \\ Industrial Management Department, Faculty of Technology, University of Vaasa, Vaasa 65101, Finland, \\ Alireza.aslani@uva.fi (corresponding author), Marja.naaranoja@uva.fi
}

\begin{abstract}
Innovation management in the primary health care centers is one of the important debates among the governments and academic forums. Although the number of studies in the field of innovation in health care sectors has increased over the last 10 years, little is known about the conditions for the successful implementation of innovations in the health care centers. In this paper, we review and assess the situation of Finnish health care centers from innovation management viewpoint. We try to answer one of the important questions designed by policy makers: "How can Finnish health care centers move toward systems that continuously improve their innovation and creativity?" The presented framework describes the main characters and dimensions of diffusion of ideation and innovation in the health care centers.
\end{abstract}

Keywords: Health care centers, Ideation, Diffusion of creativity and innovation, Finland

\section{Introduction}

The main tasks of all public health care systems in different countries are to maintain access and equity of optimal health care among the citizens. The level and quality of each health care system depends on the factors such as population, GDP, governmental budget, health expenditure, and country's age pyramid (Gray, 2012). In recent decades, Finland's health care system has developed rapidly and stands among the world's top health care systems. Publicly owned and operated hospitals, tax-based funding, health access based on residency, and comprehensive coverage make the main body of Finnish system. In response, high proportion of GDP spent on health and social services, high level of social benefits, free or subsidized health services, equal income distribution, and gender equality are the results of these policies. Although this level of standards has brought social welfare for Finland, the reality is something considerably complex. Concerns and trends such as aging population, shortage of native manpower, advances in medical science, and increasing expectations along with budget limitations threaten the Finnish health care system. For instance, the aging Finnish workforce affects patient demographics and availability of nurses and clinicians. This means upcoming wave of retiring health care experts will occur at the time when Finland needs more manpower in the health care sector (HCS). In a larger scale, other Nordic countries and even Europe have similar challenges. Therefore, health care systems should focus on series of strategies and solutions to overcome the concerns. Studies show that prevention and incentives strategies among population, technological development in the systems, diffusion of IT systems, privatization of the health care centers, increasing the public awareness via social media are the most important polices that governments and public policy makers have implemented in their strategies (Sato, 2012).

All strategies have used a kind of innovation that shows the role of creativity and ideation in the HCS. Innovation is an important means of value creation and improvement for clients. This is particularly important in the health care systems where much progress has occurred in various fields of clinical research and medical technology. As primary health care centers (HCC) are directly working with almost all population, innovation dealing with the organization of care centers and professionals has great potential for value creation. However, adoption of innovation in the HCS and especially HCCs is recognized as a complex process. While by innovation, we mean an idea or practice that is perceived new by a person or other unit of adoption, it is difficult to identify and even understand creative and innovative ways in the HCCs. 
This article in the frame of a case study reviews and assesses the situation of Finnish health care centers (FHCC) from innovation management viewpoint. The work also tries to answer to one of the important questions designed by public policy-makers titled "How HCCs in Finland can move toward a system that continuously improve their creativity and innovation?" An innovative framework based on an extensive action research is presented to describe main characters and dimensions of the diffusion of innovation in the HCCs.

\section{Brief review of Finnish health care system}

The initial preparations to success of Finnish health system were established in the 1960s and 1970s (Teperi et al., 2009). Heavy investments in building hospitals and creation of primary networks of HCCs are examples of those activities. The HCCs have an important role in the Finnish primary HCS with a wide range of services such as GP services, physiotherapy, maternity and child welfare, dental care, school health care, psychologist service. The majority of these services are organized and provided by municipal health care system. Municipalities provide adequate and suitable health services for their residents (Rantanen et al., 2001). Around 336 municipalities are currently working in Finland that provide two thirds of public services. To fund the services, municipalities levy taxes between $16 \%$ and $22 \%$ and receive state subsidies. Indeed, twenty hospital districts provide the specialist cares in the municipal system with one or multi hospitals under their supports (Teperi et al., 2009). In addition to the public municipal system, private health care, excluding occupational services, accounts for $6 \%$ of total health care expenditure.

Finland was the first country in Europe that implemented the Act on the Status and Rights of Patients in 1993 (Magnussen et al., 2009). The Act recognizes the patient right to information and see any relevant medical documents, informed consent to treatment, and to complain and to autonomy. A patient ombudsman is also required in all centers providing medical treatment, to inform patients on their rights and, if needed, to help to make a complaint (Magnussen et al., 2009).

In 2010, the total health expenditure (per capita) in Finland was 2,504€ which had about $4 \%$ growth compared to 2006 (2,586 €) (OECD, 2011, OECD, 2012). Total health expenditure as a share of GDP was also about $8.9 \%$ of GDP in 2010 with about $8 \%$ growth compared to 2006 (about 8.2\%) (OECD, 2012).

\section{Challenges of healthcare sector in Finland: Importance of innovation}

Although fair distribution of services by providing HCCs is one of the longstanding targets of Finnish health care policy, concerns exist in the HCCs. First, the welfare government model runs the danger of turning residents into passive recipients rather than active consumers or co-producers of services. This has been particularly evident in the health care sector (Magnussen et al., 2009). On the other hand, aging population is a big challenge for Finland and Nordic countries from social viewpoint at this time. This brings cost increasing in the health care system, decreasing workforce and thereby declines the government's incomes. Thereby, the fiscal sustainability of the system will be under pressure and reducing benefits, increasing taxes affect the health care system (Vuorenkoski et al., 2007). Simultaneously, shortage in native manpower and increasing expectations are two of other important challenges (Winblad et al., 2010).

On the other hand, because the Finnish health care system is a decentralized system, national steering is rather weak. As each municipality specifies its own scope of coverage within general limits set by national legislation, the amount of services differ geographically in the HCCs of municipalities. In other words, significant differences stand across municipalities in resource allocation for health care delivery in the HCCs. The differences are because of factors such as financial resources, availability of health professionals (Teperi et al., 2009).

In response, Finnish policy makers have tried to understand these challenges and consider for creating a number of ambitious innovations in the HCCs among the professionals to increase the efficiency of the system. Examining values and goals of HCCs that form the basis for structural and institutional arrangements are examples of these efforts. This shows the degree that HCCs are changeable and ready for innovation's mechanisms. Therefore, ideation in structures and process are the keys for innovation improvement in the HCS and HCCs. Despite some success, the evaluations show that the total impact of innovation among the Finnish manpower has not met expectations (Paakkonen and Seppala, 2012).

\section{Levels and terms of innovation in the health care centers}

Innovation in the HCCs can be discussed in three different levels: goals and aspirations in the HCC, institutional and structural, and systemic and institutional features operationalized in the HCCs (Figure 1).

Indeed, it can be presented in four main types known as the terms. The first innovation in the HCCs is product/Service innovation. It includes introduction or implementation of a good or service that is new or significantly improved in the HCCs (Omachonu and Einspruch, 2010). Process innovation includes implementation of a new or significantly improved process of service (e.g., equipment and/or software) (Aslani et al., 2009). Delivery innovation referees implementation of a new delivering or marketing method involving sig- 


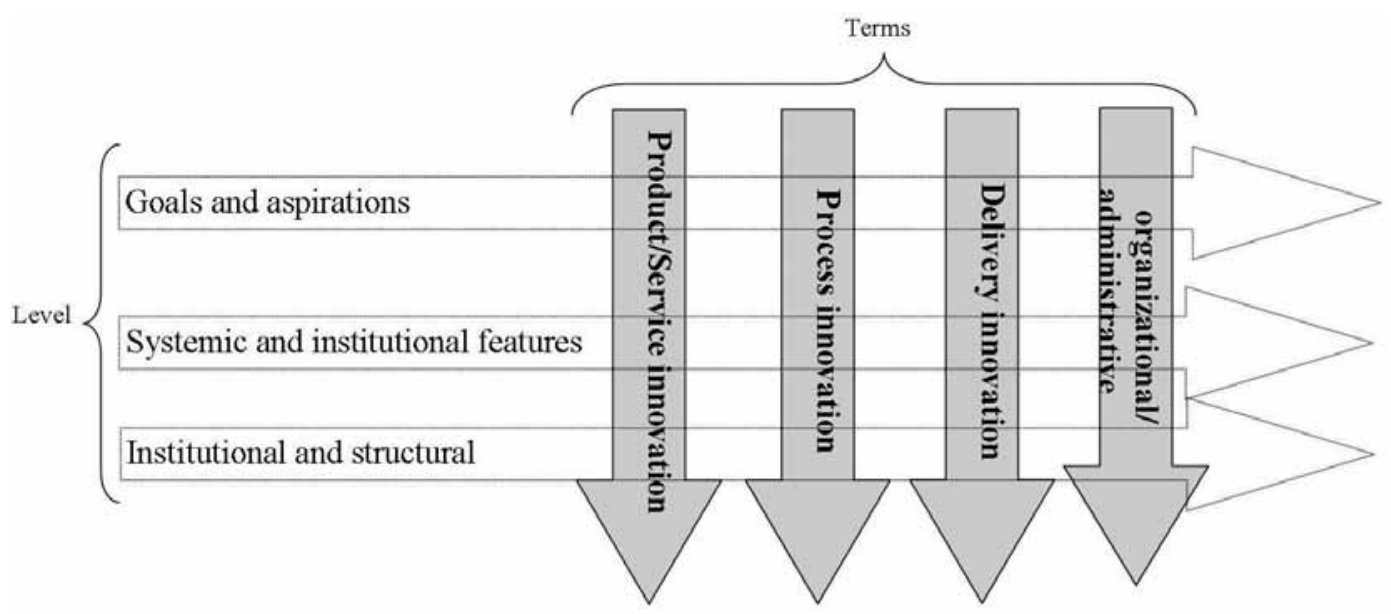

nificant changes in service design or packaging, health service placement, and care costs (Kekale and Aslani, 2011). Finally, organizational/administrative innovation introduces the implementation of a new organizational method in the HCC business practices, workplace organization, or external relations with government, municipalities, and other HCCs' networks.

\section{Research method}

This investigation is a part of a national project to study collaborative innovation management in the Finnish HCS. The contributions extracted based on an action research done during a period of eight months in two HCCs working in two municipalities of Finland. Due to the role of personal and patients in this study, as well as direct engagement of researchers during research and observation, an action research should be implemented. Action research is an evidence-based research that links directly to practice. Figure 2 illustrates a simple model of the typical action research process that was implemented in this article. Each cycle includes four steps: plan, act, observe. and reflect.

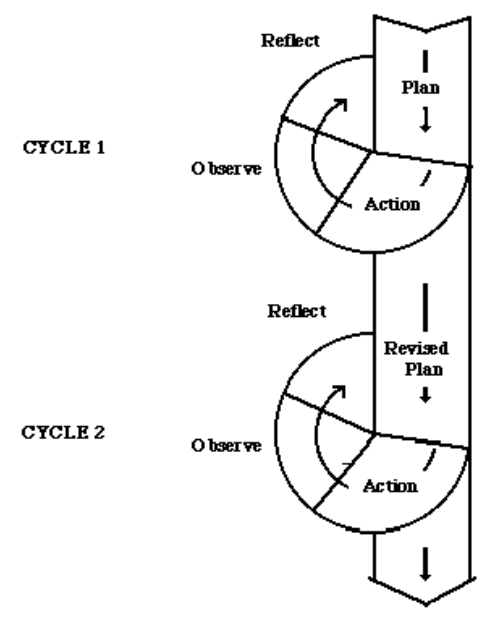

Figure 2. Simple Action Research Model (Gerald, 1983)
To assess and identify the situation of creativity and innovation in the HCCs, two different questionnaires for nurses, and head of the departments (professionals) and doctors were designed. The researchers asked respondents to explain their work and amount of ideation or innovation that have in their daily tasks. Further, importance of ideation in their work, and questions related to encouragement schemes to appear creative and innovative ideas were asked. The questions were open response and the researchers directly interviewed with all respondents. The average time of each interview was 30 minutes. A sample of 36 interviews including the nurses, head of the nurses, and doctors was selected among of 78 professionals. In light of the numbers of the professionals who are working in the centers, the number of sample is quite enough to the have a valid analysis.

To organize and extract the results, NVIVO 9 software was used (Aslani et al., 2012a). NVIVO is one of the best research software produced by QSR Company to support qualitative and mixed methods researches. The software helped us in three main ways: managing data, managing the ideas, and querying data (Figure 3 ). This qualitative data analysis provides the possibility of identifying the key themes of diffusion of innovation in the HCCs.

\section{Discussion and analysis}

The analysis of the interviews illustrates several factors that positively or negatively affect innovation of Finnish professionals in the local level. While almost all of the respondents believe that creativity and ideation can play an important role in their work and patient satisfaction, most of them do not ensure about innovatively working in their organization. In some cases, they even do not know how the creativity and ideation can be implemented in the HCCs. Therefore, low efficiency and motivation, poor innovation, and lack of responsiveness to patients' needs can be expected in such level of awareness among the HCCs' professionals. This proves 
Figure 3. Data analysis by using NVIVO 9

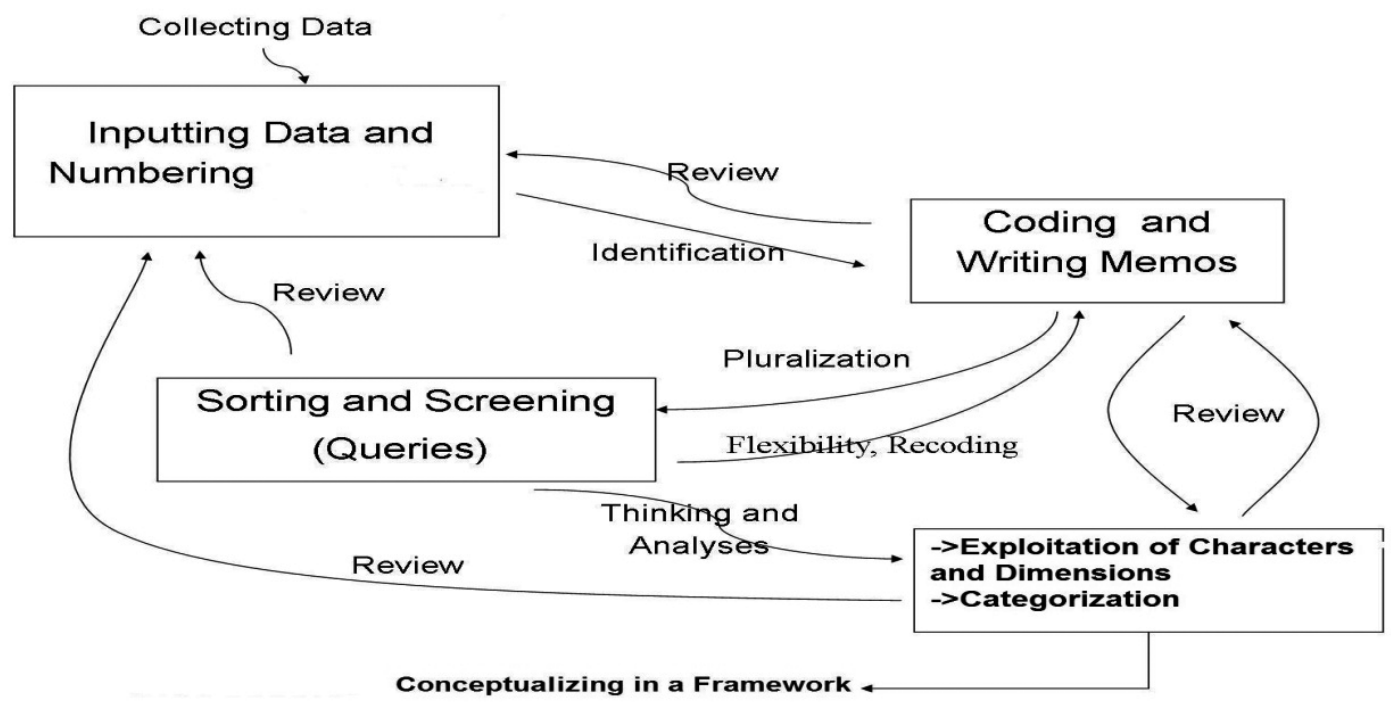

the complexity of innovation concepts in the HCS. The analysis shows that there are determinant factors affect innovativeness of the professionals in the HCCs. These factors are essential to design an appropriate and valuebased innovation. We categorize the factors in three main characters: individual, systematic, and structural.

Figure 4 illustrates general framework of the ideation and innovation processes in the HCCs analyzed by NVIVO 9. Since diffusion of innovation in the HCS is sorted as a strategic decision process, the proposed framework is based on a strategic decision making model (Rajagopalan et al., 1993). Therefore, three aspects of enablers, processes, and outcomes are comprised in the framework. "Enablers" are the characters that affect diffusion of innovation within or across work units and departments. In other words, innovation enablers include the efforts that nurses, doctors, managers, and policy makers implement to provide the emergence possibility of creative and innovative ideas and methods in the HCCs (process dimension). The "process" dimension of innovation refers to how the health care's employees implement the enablers of innovation in their work-related experience and expertise (adoption process). Several strong research works have been independently done to consider this dimension (Fleuren et al., 2004). Finally, the "outcomes" dimension reveals the effects of the degree of creativity and innovation management effectively achieved on the health care performance indicators.

\section{a. Individual characters}

The success of creativity and innovation in an organization depends on individual characters (Aslani et al., 2012b). The analysis of responses shows that professionals' attitudes, perception, motivation, personality, biographical factors, and job satisfaction are the main important characters affect the level of creativity and innovation in the HCCs (Aslani et al., 2012b). Table 1 shows the sub-factors of each character. While Finnish professionals are not sure about application of innovation and creative idea in the HCCs, this is a big gap among the targets and execution for a government with a high attention to innovative issues. The barriers of creativity and innovation from individual characters can be reviewed biologically, socially, psychologically, and historically (Aghaei, 2008, Ferlie et al., 2008).

Table 1. Sub-factors of individual characters

\begin{tabular}{|l|l|}
\hline \multirow{2}{*}{ Professionals attitudes } & $\begin{array}{l}\text { - Trust, } \\
\text { - Belief, } \\
\text { - Reciprocity norms, }\end{array}$ \\
\hline Perception & $\begin{array}{l}\text { - Importance of innovation as a } \\
\text { power, } \\
- \text { Perceived relative advantages, }\end{array}$ \\
\hline Motivation & $\begin{array}{l}\text { - External or internal motiva- } \\
\text { tions such as government sup- } \\
\text { ports, job promotion }\end{array}$ \\
\hline Biographical factors & $\begin{array}{l}\text { - Age, } \\
- \text { Gender, } \\
- \text { Tenure }\end{array}$ \\
\hline
\end{tabular}

\section{b. Systematic characters}

Systematic characters describe factors related to organization of the HCCs and formal and informal groups. The analysis of interviews indicates that the possible communication among the professionals, organizational culture, team working, supports from/of the supervisors 
Figure4. General framework of innovation management in the health care sector

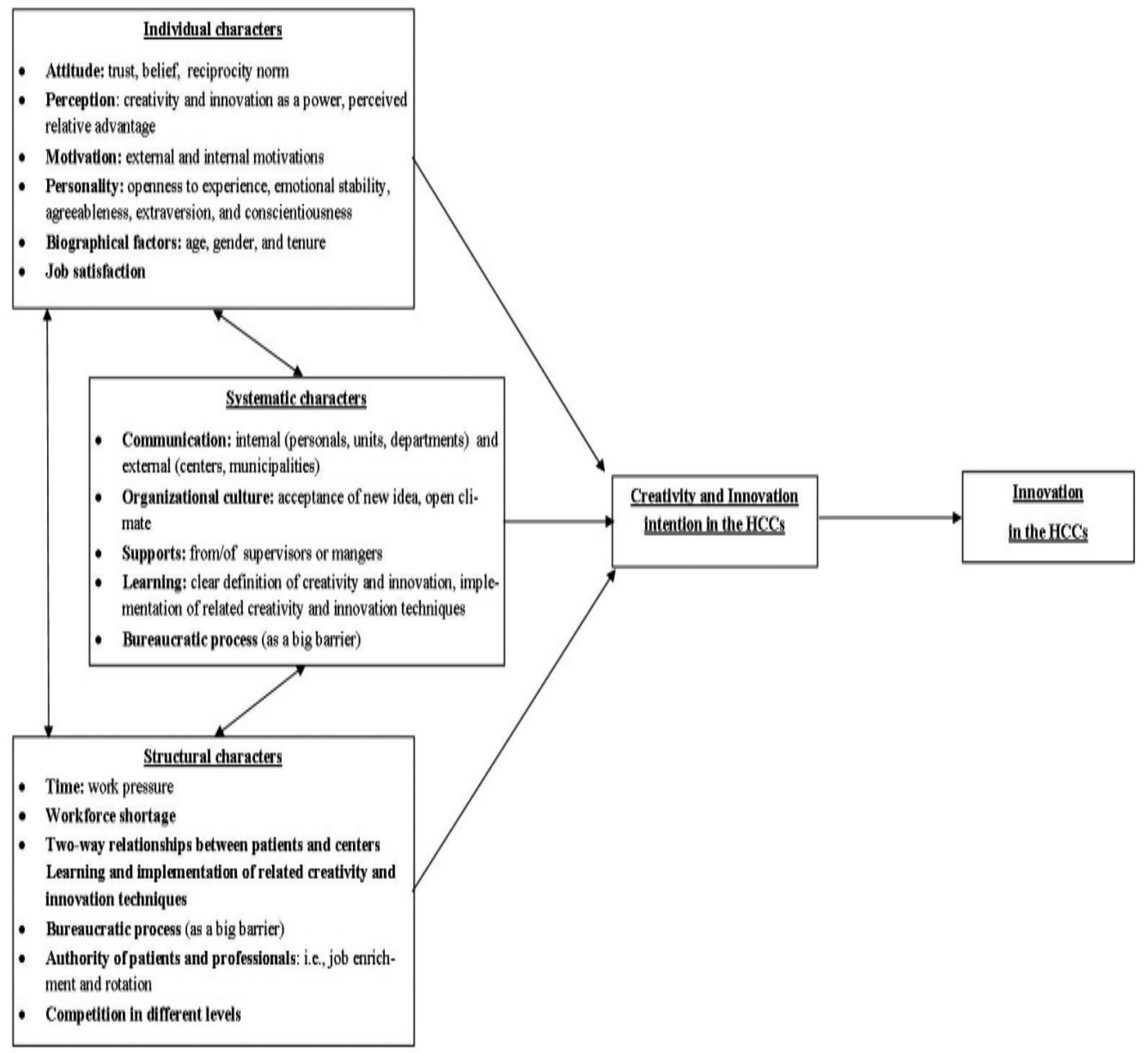

\section{Enablers dimension}

\section{Process dimension}

\section{Outcome dimension}

or mangers, learning and implementation of creativity and innovation techniques, and bureaucratic process along with long waiting lists (in different levels from patients to personnel) are the most important systematic characters that affect diffusion of innovation in the HCCs (Aslani et al., 2012c). An organizational environment that encourages new problem-solving methods and creative ideas is an important gap in the Finnish HCCs. To provide this environment, applications of related creativity and innovation techniques is an appropriate strategy (Proctor, 2005). In fact, in searching to find the solutions of a problem, the activity of a person decreases and stops after finding the first/two solutions based on his/her mental characters. Application of creativity techniques will be effective to spread decision space (Hyginz, 2002). A survey shows that about 80\% Austrian companies have used creativity techniques at least once, and $69 \%$ of them believe they are useful for generating ideas and solving daily problems (Aslani et. al., 2012d). 
Therefore, creativity techniques should be an important part of innovation management in the HCCs.

\section{c. Structural characters}

The structural characters discuss about issues that are beyond of behavioral aspects. For example, one of the main barriers of creative idea is the lack of time available for nurses and doctors to think innovatively in the Finnish HCCs. The analysis of interviews shows that almost all of the respondents believe that the workforce shortage is the main barrier for them to think innovatively. As this caused work pressure, it even harms the staff's motivation. Two-way relationships between patients and centers (in order to individual cares or even suggestions for working better) are also characters that can effect on diffusion of ideation and innovation in the HCCs. In addition, authority of patients (e.g., increasing patient choice to choose the centers, normal and daily checkup) and staff in their tasks (job rotation and enrichment) are the factors affect the HCCs innovations. Finally, competition in different levels from HCC's staff to HCCs is an important driver to encourage centers and professionals to think innovatively.

\section{Conclusion}

Studies show that the application of innovation in the health care sector is usually defective with ambiguity and complexity. On the other hand, aging populations, rising public expectations, progress in medical science and technologies, and other trends generally increase the need for changes in the health care systems. This article tried to answer to one of the important challenges of the Finnish health care system related to the diffusion of innovation in the health care centers. As discussed, the main enablers of the development of ideation and innovation in the HCCs can be categorized in three main types: individual, systematic, and structural. Each category includes different themes that provide successful implementation of innovation management process.

Importance of each factor or character, effects of centralization or decentralization of fiscal authority into larger regional on HCCS's innovation, and the amount of correlation between different factors and diffusion of innovation in the health care centers are subjects for future research that are suggested by authors.

\section{Literature}

Aghaei, T. (2008). Creativity and Innovation in Human and Organization, Terme, Tehran.

Aslani, A., Naaranoja, M. \& Zakeri, B. (2012a).The prime criteria for private sector participation in renewable energy investment in the Middle East (case study: Iran), Renewable and Sustainable Energy Reviews, 16(4), 1977-1987, http://dx.doi.org/10.1016/j. rser.2011.12.015

Aslani, A., Mousakhani, M., \& Aslani, A. (2012b). Knowledge Sharing: A Survey, Assessment and Directions for Future
Research: Individual Behavior Perspective, World Academy of Science, Engineering and Technology, 6(68), 310-314.

Aslani, A., Naaranoja, M. \& Kekale, T. (2012c). Application of Creativity Techniques in the Creation of Organizational Strategies, International Journal of Engineering Business Management, 4(14), http://dx.doi.org/10.5772\%2F51359

Aslani, A., Helo, P. \& Naaranoja, M. (2012d). Development of Creativity in Concurrent Engineering Teams, American Journal of Industrial and Business Management, 2(3), 77-84, http:// dx.doi.org/10.4236\%2Fajibm.2012.23010

Aslani, A., Mohaghar, A. \& Rabiee, A. (2009). Identification and Ranking of the Effective Criteria in Creation of Successful Organizational Strategies, In: Proceedings of 7th International management conference, Tehran, [in Persian], 189-200.

Ferlie, E., Fitzgerald, L., Wood, M. \& Hawkins, C. (2005). The nonspread of innovations: the mediating role of professionals, Academy of Management Journal, 48, 117-134, http://dx.doi. org/10.5465\%2FAMJ.2005.15993150

Fleuren, M., Wiefferink, K. \& Paulussen, T. (2004). Determinants of innovation within health care organizations: Literature review and Delphi study, International Journal for Quality in Health Care, 16(2), 107-123, http://dx.doi. org/10.1093\%2Fintqhe\%2Fmzh030

Gerald, I.S. (1983). Action Research: A Sociotechnical Systems Perspective, London, Sage Publications.

Gray, M. (2012). Value: Operations Research and the new health care paradigm, Operations Research for Health Care, 1(1), 20-21, http://dx.doi.org/10.1016\%2Fj.orhc.2012.01.002

Hyginz J.M. (2002). 101 creative problem solving techniques, New Management Pub. Co. US.

Kekale, T. \& Aslani, A. (2011). Identification and Ranking of Related Creativity and Innovation Techniques with Creation of Collective Strategy by Using MADM Models Based on Fuzzy Approach, In: Proceedings of 8th International Conference of Management, Tehran, Sharif U. Tech and CIVILICA, ISSN 1735-554.

Magnussen, J., Vrangbaek, K. \& Saltman, R.B. (2009). Nordic Health Care Systems- Recent Reforms and Current Policy Challenges, McGraw Hill, New York

OECD. (2013). Health at a Glance 2012: OECD Indicators, OECD Publishing, Paris.

OECD. (2011). Health at a Glance 2011: OECD Indicators, OECD Publishing, Paris.

Omachonu, V.K. \& Einspruch, N.G. (2010). Innovation in Healthcare Delivery Systems: A Conceptual Framework, The Innovation Journal: The Public Sector Innovation Journal, 15(1), Article 2, available at: http://www.innovation.cc/scholarly-style/omachonu_healthcare_3innovate2.pdf

Paakkonen, J. \& Seppala, T. (2012). Dimensions of health care system quality in Finland, Government Institute for Economic Research, Working Papers.

Proctor, T. (2005). Creative Problem Solving For Managers, Oxon, Routledge.

Rajagopalan, N., Rasheed, A.M.A. \& Datta, D.K. (1993). Strategic decision processes: critical review and future directions, Journal of Management, 19(2), 349-84, http://dx.doi.org/10.1177\% 2F014920639301900207

Rantanen, J., Kauppinen, T., Toikkanen, J. Kurppa, K., Lehtinen, S. \& Leino, T. (2001). Work and health country profiles: Country profiles and national surveillance indicators in occupational health and safety, Finnish Institute of Occupational Health.

Sato, A. (2012). Does socio-economic status explain use of modern and traditional health care services?, Social Science \& Medicine, 75(8), 1450-1459, http://dx.doi.org/10.1016\%2Fj. socscimed.2012.05.032 
Teperi, J., Porter, M., Vuorenkoski, L. \& Baron, J. (2009). The Finnish Health Care System: A Value-Based Perspective, SITRA report, available at: http://www.isc.hbs.edu/pdf/Finnish_Health_Care_ System_SITRA2009.pdf

Vuorenkoski, L., Bäckmand, H., \& Korhonen, J. (2007). Menetetyt elinvuodet. PYLLindeksi väestön hyyvinvoinnin mittana [Potential years of life lost PYLL-rate in monitoring the wellbeing of a population], Suomen Lääkärilehti, 62: 305-9.

Winblad, I., Viramo, P., Remes, A., Manninen M. \& Jokelainen, J. (2010).Prevalence of dementia - a rising challenge among ageing populations, European Geriatric Medicine, 1(6), 330-333, http://dx.doi.org/10.1016\%2Fj.eurger.2010.10.002

\section{Acknowledgement}

This research is a part of OSUVA project funded by Finnish Funding Agency for Technology and Innovation (TEKES), Finland.
Alireza Aslani, project researcher and lecturer, is a doctoral student in the Department of Production (Industrial Management) at the University of Vaasa, Finland. His priorities for research are quantitative decision-making, public policy, innovation management, and system dynamics.

Marja Naaranoja is an associate professor of knowledge management in the Department of Production (Industrial Management) at the University of Vaasa, Finland. She has professional research experiences in the fields of change management, knowledge management, and innovation management in both industry and health care sectors. 